\title{
Lynch syndrome: current status of CRC in Biotechnological and Biomedical fields
}

\author{
Arnaud Martino Capuzzo \\ Department of Veterinary Medicine, University of Milan, Italy.
}

Keywords: Lynch syndrome, CRC, Cancer, Biotechnology, Biomedical.

\begin{abstract}
Lynch syndrome (LS) is an autosomal dominant genetic condition caused by mutations in the DNA mismatch repair (MMR) genes in the germline. Colorectal cancer and/or LS-associated cancer are more likely in people who carry pathogenic mutations in these genes. Cancers of the endometrium, small intestine, stomach, pancreas, and biliary tract, ovarian, brain, upper urinary tract, and skin are among the cancer types linked to LS. The criteria for a clinical diagnosis of LS, as well as the processes for genetic testing to identify carriers of pathogenetic mutations in MMR genes, have been known for a long time. The precise description of the pathogenicity associated with MMR genetic variants is critical in the mutation detection analysis, especially in order to enroll mutation carriers in endoscopic surveillance programs that are more suited to them. As a result, this may aid in the improvement of LS-related cancer prevention efforts. In this review, we discuss recent advances in the molecular genetics of LS.
\end{abstract}

\section{Introduction}

More than 100 cancer-prone genetic syndromes have been identified, with many of them containing well-defined cancer-causing germline mutations. Observational studies in cancer-prone families have allowed clinicians, molecular geneticists, and genetic counsellors to identify individuals who are at an extremely high lifetime risk of developing cancer and to provide cancer prevention surveillance, whereas family members without the causative mutation are at a general population risk for the syndrome-related cancers (Sinicrope, 2018). Lynch syndrome (LS), also known as hereditary nonpolyposis colorectal cancer (HNPCC), is the most common hereditary type of colon cancer, accounting for about 3\% of all new cases. Aside from early-onset colon cancer with proximal predominance and an excess of synchronous and/or metachronous colon 
cancer, endometrial and ovarian cancers, as well as cancers of the stomach, small bowel, prostate, breast, brain, and hepatobiliary tract, are the cancers most frequently associated with LS (Tiwari et al., 2016). LS is a susceptibility to a variety of malignancies, mostly of the colorectum and endometrium, in which MMR activity is diminished. Autosomal dominant heterozygous germline mutations in one of the four critical MMR genes mutL homologue 1 (MLH1), mutS homologue 2 (MSH2), MSH6 or post meiotic segregation increased 2 (PMS2), which result in loss of function of the encoded protein, induce this cancer propensity (Bolan et al., 2013). Downstream genetic alterations accumulate in LS-associated malignancies, which develop after the somatic loss of function of the remaining wild-type allele of the damaged MMR gene. As a result, the goal of this review paper is to focus on the current situation of the Lynch syndrome in biotechnological and biomedical domains (Schmeler et al., 2006).

\section{Background of Lynch syndrome}

The history of LS begins at the University of Michigan, USA, in 1895 with Warthin. Warthin was strongly impacted by the account of his seamstress, who blamed the many deaths in her family, particularly the colorectum, stomach and uterus, to her despair. Warthin began to document her family history of medical, cancer, and familial pathology results (Linder et al., 2006). In 1962, Henry Lynch had a family history similar to that of Warthin's seamstress during his residential residency. While he was suffering from delirium tremens, Lynch said he was drinking because he had died from colorectal cancer (CRC) because everyone died of this disease in his family. Lynch developed a detailed family history, revealing excessive CRC instances transmitted over several generations. Lynch's first thoughts were of familial adenomatous polyposis (FAP), which had previously been the most common diagnosis in CRC-prone families (Lynch et al., 2009). The fact that both families were raised in Midwestern rural regions where they were exposed to pesticides and other potential carcinogens in the agricultural industry seemed to support this theory. Lynch was recruited to research Warthin's Family $G$ by the then-chairperson of pathology at the University of Michigan School of Medicine. This prompted a thorough examination of family documents. Following that, Lynch and Anne Krush, a medical social worker, travelled to Germany, where the majority of Family G originated, and gathered additional evidence of cancer propensity (Hampel et al., 2005). 


\section{Risk factors}

Precancerous lesions cause around $80 \%$ of colorectal malignancies. Long have lifestyles and familiarity been questioned as factors that increase the risk of various diseases? Dietary variables, such as red meat and sausage intake, processed flours and sugars, obesity and a sedentary lifestyle, smoking, and excessive alcohol use, stand out among the former. In addition to the variables stated above, fresh seasonal fruit and vegetables, unrefined carbs, vitamin D, and calcium, as well as the prescription of non-steroidal anti-inflammatories at regulated dosages and timings, provide protection. Approximately one third of CRC tumors have familiar characteristics attributable to hereditary susceptibility: only a part of this familial risk (2-5 percent) is attributable to syndromes in which genetic mutations associated with increased risk of colorectal cancer have been identified. Among these, syndromes characterized by the onset of polyps, such as familial adenomatous polyposis (FAP) and non-polyposic ones such as Lynch syndrome.

\section{CRC staging}

The stage of colorectal cancer determines how far it has spread. Staging is critical for determining treatment options as well as establishing prognosis. Three parameters are used in the TNM staging system: T stands for the size of the original tumor and its invasion of surrounding tissues; $\mathrm{N}$ stands for the involvement of regional lymph nodes close to the tumor; and $\mathrm{M}$ stands for the occurrence of distant metastases. Depending on the size of the tumor (T), the number of lymph nodes involved $(\mathrm{N})$, and the presence or absence of distant metastases, each characteristic is assigned a number and potentially a letter (M). Tab1, Tab2, Tab3, and Tab4 show the 2009 TNM-UICC classification for the TNM system, which is based on current guidelines.

\begin{tabular}{|l|l|}
\hline \multicolumn{1}{|c|}{ T-Class } & \multicolumn{1}{c|}{ Description } \\
\hline Tx & Primary tumor not definable \\
\hline T0 & Primary tumor not detectable \\
\hline Tis & $\begin{array}{l}\text { Carcinoma in situ: intraepithial or invasion of } \\
\text { the lamina propria and this may include tumor } \\
\text { cells confined within the glandular basement } \\
\text { membrane (intraepithelial) or the lamina } \\
\text { propria (intramucosal) }\end{array}$ \\
\hline
\end{tabular}




\begin{tabular}{|l|l|}
\hline T1 & Tumor that invades the submucosa \\
\hline T2 & Tumor that invades the proper muscular layer \\
\hline T3 & $\begin{array}{l}\text { Tumor with invasion through the proper } \\
\text { muscle in the subrosa or in the tissues not } \\
\text { covered by the peritoneum }\end{array}$ \\
\hline T4 & $\begin{array}{l}\text { Tumor that directly invades other organs or } \\
\text { structures and perforates the visceral } \\
\text { peritoneum }\end{array}$ \\
\hline T4a & Tumor that perforates the visceral peritoneum \\
\hline T4b & Cancer that invades other sites \\
\hline
\end{tabular}

Tab1. 2009 TNM-UICC classification : T parameter. Primary tumor size and invasion of surrounding tissues.

\begin{tabular}{|l|l|}
\hline \multicolumn{1}{|c|}{ N-Class } & \multicolumn{1}{c|}{ Description } \\
\hline Nx & Regional lymph nodes not evaluable \\
\hline N0 & No metastasis to regional lymph nodes \\
\hline N1 & Metastases in 1-3 regional lymph nodes \\
\hline N1a & Metastasis in 1 lymph node \\
\hline N1b & Metastasis in 2-3 lymph nodes \\
\hline N1c & $\begin{array}{l}\text { Satellite tumor deposits in the subserosal or } \\
\text { non-peritonealized and perirectal tissues } \\
\text { without evidence of regional lymph node } \\
\text { mestasis }\end{array}$ \\
\hline
\end{tabular}




\begin{tabular}{|l|l|}
\hline & \\
\hline $\mathrm{N} 2$ & Metastases in 4 or more regional lymph nodes \\
\hline $\mathrm{N} 2 \mathrm{a}$ & Metastasis in 4-6 lymph nodes \\
\hline $\mathrm{N} 2 \mathrm{~b}$ & Metastasis to 7 or more lymph nodes \\
\hline
\end{tabular}

Tab2. 2009 TNM-UICC classification: $\mathbf{N}$ parameter. Involvement of regional lymph nodes adjacent to the tumor.

\begin{tabular}{|l|l|}
\hline \multicolumn{1}{|c|}{ M-Class } & \multicolumn{1}{c|}{ Description } \\
\hline Mx & Distant metastases cannot be ascertained \\
\hline M0 & Absence of distant metastases \\
\hline M1 & Distant metastasis \\
\hline M1a & $\begin{array}{l}\text { Metastases confined to an extra-regional } \\
\text { organ and lymph nodes }\end{array}$ \\
\hline M1b & $\begin{array}{l}\text { Metastasis to more than one organ or to the } \\
\text { peritoneum }\end{array}$ \\
\hline
\end{tabular}

Tab3. 2009 TNM-UICC classification: M parameter. Presence of distant metastases.

\begin{tabular}{|l|l|}
\hline \multicolumn{1}{|c|}{ Stage } & Description \\
\hline Stage 0 & Tis, N0, M0 \\
\hline & T1, N0, M0 \\
\hline
\end{tabular}




\begin{tabular}{|l|c|}
\hline & T2, N0, M0 \\
\hline Stage IIa & T3, N0, M0 \\
\hline Stage IIb & T4a, N0, M0 \\
\hline & T4b, N0, M0 \\
\hline & T1-2, N1a-c, M0 \\
& T1-2, N2a, M0 \\
\hline Stage IIIb & T3-T4a, N1a-c, M0 \\
\hline & T2-3, N2a, M0 \\
\hline & T1-2, N2b, M0 \\
\hline Stage IVa & T4a, N2a-b, M0 \\
\hline Stage IVb & T3, N2b, M0 \\
\hline
\end{tabular}

Tab4. Division into stages. The current report provides a comprehensive overview of colorectal cancer.

\section{Clinical criteria}

The Amsterdam Criteria (AC) and Bethesda guidelines are used to identify families affected with LS. Since 1990, the Amsterdam clinical criteria have been used to select families appropriate for molecular investigation. Those criteria, AC II to cover other LS-related malignancies, have subsequently been updated. The Bethesda standards, which are less stringent than the AC recommendations, were later created and take into account the MSI-status discovered in tumoral tissue. The National Cancer Institute-recommended 'Panel of Bethesda' includes five 
microsatellites: two mononucleotide repeats (BAT25, BAT26) and three dinucleotide repeats (D2S123, D17S250, D5S346) that are evaluated on tumoral DNA of patients with probable LS (Vasen et al., 1999). Subsequently the panels included other microsatellite sequences: NR21, NR22 and NR24, repeats of mononucleotides to increase the sensitivity rate and the Bethesda guidelines' predictive specificities; three of the replicates (NR21, NR22 and NR24) are the Pentaplex Panels with BAT25 and BAT26 (Sehgal et al., 2014). In a schematic way, the criteria and guidelines have been reported in Tab.5.

\begin{tabular}{|c|c|}
\hline \multicolumn{2}{|c|}{ Amsterdam I Criteria } \\
\hline \multicolumn{2}{|c|}{ At least three relatives with histologically confirmed CRC are required. } \\
\hline 1. & One is a first-degree relative of the other two \\
\hline 2. & $\begin{array}{l}\text { At least two successive generations are } \\
\text { affected }\end{array}$ \\
\hline 3. & $\begin{array}{l}\text { At least one of the relatives with CRC is } \\
\text { diagnosed at }<50 \text { years of age }\end{array}$ \\
\hline 4. & $\begin{array}{l}\text { Familial adenomatous polyposis (FAP) has } \\
\text { been excluded }\end{array}$ \\
\hline \multicolumn{2}{|c|}{ Amsterdam II Criteria } \\
\hline \multicolumn{2}{|c|}{$\begin{array}{l}\text { At least three relatives with an LS-associated cancer (endometrium, stomach, ovary, ureter } \\
\text { or renal pelvis, brain, small bowel, hepatobiliary tract and skin) }\end{array}$} \\
\hline 1. & One is a first-degree relative of the other two \\
\hline 2. & $\begin{array}{l}\text { At least two successive generations are } \\
\text { affected }\end{array}$ \\
\hline 3. & $\begin{array}{l}\text { At least one of the LS-associated cancers } \\
\text { should be diagnosed at <50 years of age }\end{array}$ \\
\hline 4. & FAP should be excluded in any CRC cases \\
\hline 5. & $\begin{array}{l}\text { Tumors should be verified by pathology } \\
\text { whenever possible }\end{array}$ \\
\hline \multicolumn{2}{|c|}{ Bethesda Guidelines } \\
\hline \multicolumn{2}{|c|}{ Used for testing of colorectal tumors for microsatellite instability (MSI) } \\
\hline
\end{tabular}




\begin{tabular}{|l|l|}
\hline 1. & $\begin{array}{l}\text { CRC diagnosed in a patient who is <50 years } \\
\text { of age }\end{array}$ \\
\hline 2. & $\begin{array}{l}\text { Presence of synchronous or metachronous } \\
\text { colorectal or other LS-associated tumors, } \\
\text { regardless of age }\end{array}$ \\
\hline 3. & $\begin{array}{l}\text { CRC } \text { with MSI-high (MSI-H) } \text { histology }^{\mathbf{b}} \\
\text { diagnosed in a patient who is }<60 \text { years of } \\
\text { age }^{\mathbf{c}}\end{array}$ \\
\hline 4. & $\begin{array}{l}\text { CRC or LS-associated tumor diagnosed <50 } \\
\text { years of age in at least one first-degree } \\
\text { relative }\end{array}$ \\
\hline 5. & $\begin{array}{l}\text { CRC or LS-associated tumor diagnosed at any } \\
\text { age in two first- or second-degree relatives }\end{array}$ \\
\hline
\end{tabular}

Tab5. Amsterdam criteria and Bethesda guidelines. LS-associated tumors include colorectal, endometrial, stomach, ovarian, pancreas, ureter or renal pelvis, biliary tract and brain (usually glioblastoma) tumors, sebaceous gland adenomas and keratoacanthomas in Muir-Torre syndrome, and carcinoma of the small bowel. a) MSI-H in tumors refers to variations in two or more of the five microsatellite markers panels suggested by the US National Cancer Institute. b) MSI-H histology refers to the presence of tumor-infiltrating lymphocytes, Crohn disease-like lymphocytic reaction, mucinous or signet-ring differentiation, or medullary growth pattern. c) The Workshop participants couldn't agree on whether or not to include the age criteria in guideline 3; they opted to maintain the 60-year-old age limit in the guidelines. d) Criteria 4 and 5 have been reworded in the Revised Bethesda Guidelines to make them clearer.

\section{Molecular analysis}

MMR gene mutations have been linked to LS. The majority of mutations were found in the MLH1 and MSH2 genes, accounting for about 50 and 40 percent of all mutations reported, respectively; about 15-20 percent of mutations were found in the MSH6 and PMS2 genes; few pathogenetic mutations were found in the MLH3 gene, and only one heterozygous variant in the MSH3 gene has been linked to the LS phenotype so far. Small insertions/deletions or big genomic rearrangements (large deletions/insertions) are the most pathogenic variations in MMR genes, resulting in premature stop codon generation at the protein level (Koornstra et al., 2009). Several MMR gene mutations have been found as missense, silent, or intronic variants. Because the impact 
of these polymorphisms on the development of cancer is frequently disputed, they are all categorized as variants of questionable importance. A multifactorial likelihood model can be used to try to determine a pathogenetic function of VUS, according to international recommendations. This method is based on the assessment of both phenotypic and functional characteristics. The segregation analysis, in particular, should be regarded as the 'gold standard' for determining VUS pathogenicity (Carethers et al., 2014). The molecular analysis of LS starts with the MSI status assessment on tumor DNA by the use of the capillary electrophoresis analysis of the diagnosis fragment DNA. Immunohistochemistry (IHC) analysis can identify MSI at the somatic level (Vasen et al., 2013).

Instead, denaturing high-performance liquid chromatography (DHPLC) and direct sequencing for point mutations, and multiplex ligation-dependent probe amplification (MLPA) for massive rearrangements, are standard approaches for detecting mutations in MMR genes. In MMR-genes, in particular MLH1, MSH2, MSH6, and PMS2, a substantial number of variations were previously reported in insight group database. No variants were reported for the MLH3 and MSH3 genes. Literature data nonetheless reveal that patients with colorectal hereditary cancer and mutations are present in these two genes (Moreira et al., 2012). High-throughput techniques, such as nextgeneration sequencing, have now replaced older methods, allowing for the identification of a large number of genes involved in hereditary cancer types. Recent discoveries, for example, reveal that POLE and POLD1 mutations are linked to gastrointestinal cancers, with mutations in both genes seen in Lynch-like phenotypic patients (Ferrer et al., 2021).

\section{D Model system: spheroids and organoids}

The Scientific study requires the cultivation of cells outside of their natural environment in a laboratory under controlled conditions. Stem cell and cancer research, monoclonal antibody manufacturing, drug discovery, regenerative medicine, therapeutic protein production, and disease modelling are all areas where cell culture is useful. In vitro cultures can be created using cells extracted from normal or sick tissues, grown as adherent monolayers or in suspension, and established in two or three dimensions (Roberts et al., 2019). 


\section{Spheroid}

Spheroids are cell clumps growing in 3D. In comparison to their 2D culture equivalents, they are meant to more closely reflect in vivo models. Cell-cell and cell-matrix interactions are encapsulated in CRC spheroids, which are a 3D avascular model of CRC. Spheroids of CRC have been utilized to evaluate tumours growth, proliferation, invasion, micro metastasis, immune cell interactions, and drug screening (Duraturo et al., 2019). A Gene expression study was also carried out on CRC spheroids with hypoxic and necrotic areas, which revealed that these spheroids closely resemble the gene expression profile of in vivo tumours. Although experiments have been conducted using solely CRC cells to create spheroids, these spheroids do not allow for examination of the complicated TME. CRC in vivo is more appropriately represented by spheroids including stromal and immune cells (Luca et al., 2020). Incorporating stromal cells into CRC spheroids has been demonstrated to affect specific pathway expression in co-cultures versus mono-culture spheroids in studies. The Ras and nuclear factor-kappa B (NF- $\kappa \mathrm{B})$ signalling pathways are two among them. The necessity of integrating stromal cells into CRC spheroids to simulate the in vivo microenvironment is demonstrated by the association of NF-B with inflammation and CRC progression. Patient-derived primary cancer cells have been used to create CRC spheroids in recent years. The inclusion of individual patient samples further increases the possibility that spheroids using primary cells find translatable targets as they histologically resemble original tumours and display similar patterns of protein expression to the tumours in vivo (Elbadawy et al., 2018). The therapeutic potential of multiple cancer therapies may also be tested by CRC spheroids, including immune-modulatory antibodies targeting the major histocompatibility complex proteins class I of chain-related A and natural killer group A (NK) group 2, and combination therapy with interleukin-2 T-cell bis-specific antibody. Combination therapy such as 5-fluorouracil, erlotinib, and regorafenib have also been studied utilizing spheroids produced from various CRC cell lines with the inclusion of stromal cells. This research suggests that spheroids can be utilized to test treatments in a 3D microenvironment as a clinically realistic model of CRC (Castro et al., 2021).

\section{Organoids}

Organoids are now widely regarded as a superior model for studying cancer genetics, cancer processes, and antitumor drug action. Organoid technology permits normal and malignant tissues to grow for a long time without requiring genetic modifications. Organoids are a useful system for working with the CRISPR-CRISPR-associated protein 9 (CRISPR-Cas9) technology, clustered regularly interspaced short palindromic repeats (Reidy et al., 2021). Organoids are self-organizing 
models made mostly from pluripotent stem cells (hPSCs) or adult multipotent stem cells. The major distinction is that multipotent stem cells are organ-specific, whereas human pluripotent stem cells can differentiate into a variety of cell types, including stromal and immune cells. With a recent work employing intestinal stem cells to construct self-assembling intestinal organoids with crypt-like and villi-like regions that approximated the spatial organization of these structures in vivo, considerable improvements in organoid formation have been made in recent years (Castro et al., 2021). Organoids may be created from individual patient tumor samples, which means they can give similar biodiversity to in vivo tumors and could be exploited to develop patient-specific treatments. Previous research indicated that CRC organoids shared $90 \%$ of somatic mutations and had a 0.89 correlation with DNA copy number profiles between organoids and original patient biopsies. These parallels highlight the benefits of adopting organoids as a CRC model (Luca et al., 2020). CRC organoids have been employed for medication screening as well as research into the initiation, progression, and invasion of CRC. Mutations in genes coding for TGF-, wingless-related integration site (Wnt), P53, and epidermal growth factor receptor (EGFR) enhance tumor progression and metastasis, according to organoid studies. Organoids of CRC are also being employed to investigate the disease's immune modulatory capabilities. CRC organoids were cocultured with cytotoxic T-cells to investigate the immune modulatory features of CRC as well as the anti-tumor immune response of cytotoxic T-cells in vitro. CRC organoids were also used to investigate the role of leucine rich repeat-containing G-protein coupled receptor 5 positive (Lgr5+) intestinal stem cells. It was shown that Lgr5+ intestinal stem cells, which are progenitor cells for $\mathrm{CRC}$, aid in tumor growth. Many of these findings give an insight into the interactions in the TME and could outline the objectives for CRC therapy (Cohen et al., 2019). Targets for treating CRC have been identified through specific investigations. Using 19 organoid CRC lines, a high throughput drug screening analysis was carried out to find chemotherapeutic drugs and inhibitors of specific targets by screening 83 distinct drugs. In other investigations, the efficacy of CARengineered NK-92 cells as a treatment for the ubiquitous epithelial cell adhesion protein was investigated. Another study looked at how rectal organoids and patients responded to chemo radiotherapy. The use of specific organoids can be effective models for studying tumor progression, metastasis, and drug screening (Elbadawy et al., 2018). 


\section{New roles for MMR proteins}

MMR proteins, in addition to post-replicative repair, have long been recognised to have established a variety of other activities. The immunoglobulin (Ig) diversification based on the "somatic hyper mutation" (SHM) process is one of these new activities (together with the suppression of reparative recombination, encouragement of meiotic crossover, expansion of repeating triplets, and control of microRNA biogenesis). The MutS-MutL complex, in conjunction with two additional proteins, AID (activation-induced cytidine deaminase) and Pol (DNA polymerase 'error-prone'), regulates this process; MutS deficiency is linked to T lymphocyte neoplastic transformation (Sehgal et al., 2014). MMR, despite maintaining genomic stability, is responsible for up to $60 \%$ of mutations in the $\mathrm{V}$ and $\mathrm{S}$ regions of the Ig locus, which are critical for antibody diversity. As a result, a greater understanding of the complicated signalling pathways that drive antibody diversification could aid in uncovering the links between genomic integrity maintenance and cancer in the adaptive immune response (Carethers et al., 2014).

\section{Early detection of LS-mediated CRC progression}

The identification of carriers of important propensity alleles improves the quality of care for patients and families with any hereditary illness resulting in gastrointestinal tumours, such as Lynch syndrome. The goal is to reduce MMR-related hereditary colorectal cancer mortality. It has long been known that carriers of pathogenetic mutations in the MMR gene should have annual surveillance colonoscopies beginning at the age of 25 (Haider and Kang, 2015) Fig1. 


\section{Colorectal Cancer Surveillance Endoscopy in Lynch Syndrome}
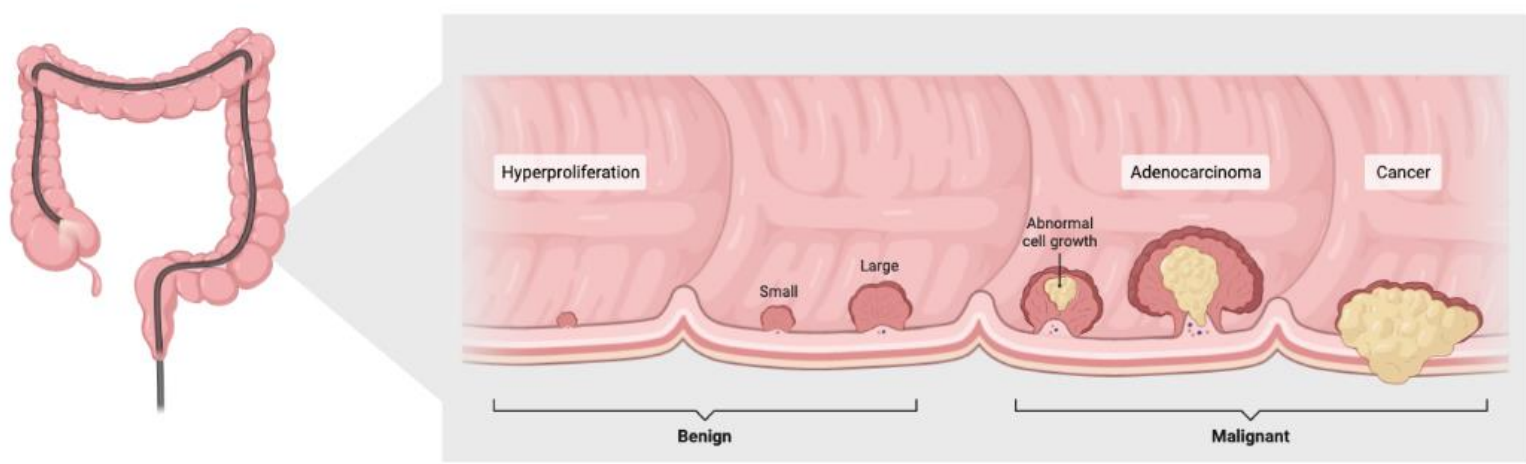

Fig1. Surveillance endoscopy in LS. Colonoscopy is recommended every 1-2 years starting at the age of 20-25, or 10 years younger than the age of the first diagnosis in the family, and every year beyond the age of 40. In LS patients, a colonoscopy should involve a thorough examination and accurate removal of all polyps, with specific focus to the right colon and a keen eye for flat lesions. Created with BioRender.com

A critical aspect in including mutation carriers in endoscopic surveillance programmes more tailored to them is the correct determination of the pathogenicity of MMR genetic variations revealed in the mutation detection analysis. As a result, this information may be useful in improving related-LS cancer prevention initiatives. MSH6 and PMS2 mutation carriers have recently been found to have a lower risk of CRC when diagnosed at a later age. Indeed, evidence from the literature supports starting colonoscopy surveillance in MSH6 and PMS2 mutation carriers at the age of 30 years, with no young index CRC, and extending the interval to two years. As a result, classifying MMR genetic variations is critical for selecting the most effective endoscopic surveillance programme and progressing toward customised therapy (Lynch et al., 2019). The discovery of a harmful germline mutation or epimutation affecting one of the linked MMR genes provides a conclusive diagnosis of LS. Tab6 discusses LS screening and management suggestions. In order to differentiate LS from other cancer syndromes with clinically comparable characteristics, molecular genetics-based diagnosis has become more important. 


\section{Screening and management}

\begin{tabular}{|l|l|}
\hline 1. & $\begin{array}{l}\text { Clinical pathology data in an extended } \\
\text { pedigree, along with the presence or absence } \\
\text { of a mismatch repair (MMR) gene mutation, } \\
\text { are used to predict cancer risk. }\end{array}$ \\
\hline 2. & $\begin{array}{l}\text { Colorectal cancer (CRC) prevention } \\
\text { necessitates a colonoscopy, which should } \\
\text { begin at the age of 18 and be repeated every } \\
\text { two years until the age of 40, then once a year } \\
\text { thereafter. }\end{array}$ \\
\hline 3. & $\begin{array}{l}\text { Gynecological cancer screening (endometrial } \\
\text { and ovarian cancer) is restricted, and there is } \\
\text { practically no viable ovarian cancer screening } \\
\text { approach. In germline MMR gene mutation } \\
\text { carriers, preventive hysterectomy and bilateral } \\
\text { salpingo-oophorectomy are done at the age of } \\
\text { 35 (or when pregnancy is no longer an } \\
\text { option). }\end{array}$ \\
\hline 4. & $\begin{array}{l}\text { Urine cytology (which requires a highly } \\
\text { trained pathologist) is combined with yearly } \\
\text { ultrasound scans starting at the age of 30 for } \\
\text { upper urological malignancy. }\end{array}$ \\
\hline 5. & $\begin{array}{l}\text { It is obvious that full patient compliance is } \\
\text { required for a clinical and prophylactic } \\
\text { surgical treatment program to be successful. }\end{array}$ \\
\hline $\begin{array}{l}\text { Identification of a deleterious germline MMR } \\
\text { gene mutation provides a definitive diagnosis. }\end{array}$ \\
\hline
\end{tabular}

Genetic counselling and testing

\begin{tabular}{|l|l|}
\hline 1. & $\begin{array}{l}\text { When feasible, a detailed cancer family } \\
\text { history with pathology evidence is necessary. }\end{array}$ \\
\hline 2. & $\begin{array}{l}\text { It is necessary to enlist the help of a qualified } \\
\text { physician, a professional genetic counsellor, } \\
\text { or a medical genetics expertise center. }\end{array}$ \\
\hline 3. & $\begin{array}{l}\text { When feasible, expand the family history to } \\
\text { four generations, including both parents, } \\
\text { progeny, maternal and paternal aunts and } \\
\text { uncles, grandparents and their siblings and } \\
\text { offspring, and, if possible, great-grandparents. }\end{array}$ \\
\hline 4. & $\begin{array}{l}\text { Reaching and connecting with relatives when } \\
\text { a family member is diagnosed with hereditary } \\
\text { cancer syndrome is difficult. Most genetic }\end{array}$ \\
\hline
\end{tabular}




\begin{tabular}{|l|l|}
\hline & $\begin{array}{l}\text { counseling sessions provide very limited } \\
\text { information to the proband's nuclear family. } \\
\text { More distant relatives are rarely tested, which } \\
\text { is regrettable because DNA testing and } \\
\text { surveillance screening in LS patients and } \\
\text { other hereditary cancer patients might save } \\
\text { their lives. }\end{array}$ \\
\hline 5. & $\begin{array}{l}\text { A detailed educational programme for the } \\
\text { entire family membership is crucial. Trust, } \\
\text { compassion and confidentiality are } \\
\text { prerequisites to success. }\end{array}$ \\
\hline
\end{tabular}

Tab6. Screening and management and genetic counselling and testing. The discovery of a harmful germline mutation or epimutation affecting one of the linked MMR genes provides a conclusive diagnosis of LS. LS screening and management recommendations are discussed and considerations regarding genetic counselling and testing are presented.

\section{Therapeutic approaches of LS-related colon cancer}

The best treatment option for people with metastatic colorectal cancer is determined by a thorough examination of the tumors clinical and genetic characteristics. The primary tumors side of the colon, the sites and burden of metastatic disease, and the mutational status of specific genes, such as KRAS, BRAF, and MSI status on tumoral DNA, must all be considered. Adjuvant chemotherapy for colorectal cancer that is not metastatic is most commonly administered with 5fluorouracil (5FU) (Reidy et al., 2021). Instead, systemic therapy with a FOLFOX- or CAPOX (capecitabine and oxaliplatin) regimen is the standard of care in some metastatic CRC cases (stage III). Anti-epidermal growth factor receptor (EGFR)-directed therapy is given to patients with leftsided malignancies and RAS wild-type tumours, while bevacizumab is given to patients with rightsided tumours or RAS mutations. In subgroup analyses of individuals with colon cancer without metastasis, adjuvant chemotherapy with 5-fluorouracil did not result in a survival advantage in patients with tumours that showed microsatellite instability or poor mismatch repair (Duraturo et al., 2019). While survival was considerably greater among patients with metastatic colon cancer who got capecitabine and oxaliplatin treatment than among those who had proficient mismatch repair. These differences are most likely connected to the lymphocytic infiltration found in MMRdeficient tumours, which defines an antitumor immune response that can be suppressed by chemotherapy's immunosuppressive effects (Cohen et al., 2019). T cells are unable to eliminate 
these tumours despite their increased immunogenicity, which is likely owing to upregulation of immune checkpoint proteins that can be blocked by checkpoint inhibitors. Immune checkpoint inhibitors have recently been discovered as anticancer medicines, and they appear promising, especially in patients with MSI who have sporadic CRC. Pembrolizumab (P) is an anti-PD-1 antibody that prevents PD-1 from interacting with PD-L1 and PD-L2 on tumour cells (Seppala et al., 2016). Patients with metastatic colorectal cancer and MSI who had previously failed to respond to cytotoxic treatments were given the antibody Pembrolizumab. Patients with LS-related CRC and those with random CRC had similar treatment responses. Furthermore, when nivolumab, another anti-PD-1 antibody, was combined with ipilimumab, an anti-cytotoxic T-lymphocyte antigen 4 (CTLA-4) antibody, responder and disease-control rates were higher than when nivolumab was used alone. In this regard, it's worth noting that these medications have shown to be effective in the treatment of MSI cancers (Yurgelun and Hampel, 2018).

\section{CONCLUSION}

The theory mainly, formulated in the middle of the last century, interprets cancer as a set of 200 diseases characterized by abnormal cell growth, released from the normal control mechanisms of the organism. The transformation process of a normal cell into a neoplastic cell takes place through various stages with accumulation of genetic, functional and morphological anomalies. Lynch syndrome (LS) is the most common hereditary type of colon cancer, accounting for about $3 \%$ of all new cases. The history of LS begins at the University of Michigan, USA, in 1895 with Warthin. MMR gene mutations have been linked to LS. Data on the early beginning of the disease, the high penetration of mutations and the demonstrated effectiveness of monitoring measures are vital in identifying which mutation causes the clinical signs of Lynch Syndrome. Furthermore, research into the molecular pathways underlying the initiation of LS-related colorectal cancer has allowed us to make great progress in the treatment of these tumor over the years. Immune checkpoint inhibitors have recently been discovered as antitumor drugs, and they appear promising, especially in patients with MSI who have sporadic CRC. Different paths and opportunities can be chosen and seized when it comes to seeking the safeguarding of an individual as a biological entity. Modern possibilities, starting from research and respect for a healthy life with a greater understanding of the connected risk factors, can induce the indifference to improve living conditions. Using the means at our disposal, with the most recent methods and peculiar characteristics, aimed at the 
resolution or taking into account of one's own entity, it is possible to have a change of perspective. We hope that some of the technological developments described in this study will make it easier to diagnose and treat LS patients and their families.

\section{REFERENCES}

Boland, C. R., \& Lynch, H. T. (2013). The history of Lynch syndrome. Familial cancer, 12(2), 145-157.

Carethers, J. M. (2014). Differentiating Lynch-like from Lynch syndrome. Gastroenterology, 146(3), 602.

Castro, F., Pereira, C. L., Macedo, M. H., Almeida, A., Silveira, M. J., Dias, S., \& Sarmento, B. (2021). Advances on Colorectal Cancer 3D models: the needed translational technology for nanomedicine screening. Advanced Drug Delivery Reviews.

Cohen, S. A., Pritchard, C. C., \& Jarvik, G. P. (2019). Lynch syndrome: from screening to diagnosis to treatment in the era of modern molecular oncology. Annual review of genomics and human genetics, 20, 293-307.

Duraturo, F., Liccardo, R., De Rosa, M., \& Izzo, P. (2019). Genetics, diagnosis and treatment of Lynch syndrome: Old lessons and current challenges. Oncology letters, 17(3), 3048-3054.

Elbadawy, M., Usui, T., Yamawaki, H., \& Sasaki, K. (2018). Development of an experimental model for analyzing drug resistance in colorectal cancer. Cancers, 10(6), 164.

Ferrer, R., Castillejo, M. I., Damaso, E., Diez, V., Garrigos, N., Molina, T., \& Soto, J. L. (2021). Co-occurrence of germline pathogenic variants for different hereditary cancer syndromes in patients with Lynch syndrome. Cancer Communications, 41(3), 218-228.

Haider, A., \& Kang, I. K. (2015). Preparation of silver nanoparticles and their industrial and biomedical applications: a comprehensive review. Advances in materials science and engineering, 2015.

Hampel, H., \& de la Chapelle, A. (2013). How do we approach the goal of identifying everybody with Lynch syndrome? Familial cancer, 12(2), 313-317.

Koornstra, J. J., Mourits, M. J., Sijmons, R. H., Leliveld, A. M., Hollema, H., \& Kleibeuker, J. H. (2009). Management of extracolonic tumours in patients with Lynch syndrome. The lancet oncology, 10(4), 400-408. 
Lindor, N. M., Petersen, G. M., Hadley, D. W., Kinney, A. Y., Miesfeldt, S., Lu, K. H., \& Press, N. (2006). Recommendations for the care of individuals with an inherited predisposition to Lynch syndrome: a systematic review. Jama, 296(12), 1507-1517.

Luca, A. C., Mersch, S., Deenen, R., Schmidt, S., Messner, I., Schafer, K. L., \& Stoecklein, N. H. (2020). Impact of the 3D microenvironment on phenotype, gene expression, and EGFR inhibition of colorectal cancer cell lines. PloS one, 8(3), e59689.

Lynch, H. T., Lynch, P. M., Lanspa, S. J., Snyder, C. L., Lynch, J. F., \& Boland, C. R. (2009). Review of the Lynch syndrome: history, molecular genetics, screening, differential diagnosis, and medicolegal ramifications. Clinical genetics, 76(1), 1-18.

Lynch, S., Pridgeon, C. S., Duckworth, C. A., Sharma, P., Park, B. K., \& Goldring, C. E. (2019). Stem cell models as an in vitro model for predictive toxicology. Biochemical Journal, 476(7), 1149-1158.

Moreira, L., Balaguer, F., Lindor, N., De la Chapelle, A., Hampel, H., Aaltonen, L. A., ... \& EPICOLON Consortium, F. T. (2012). Identification of Lynch syndrome among patients with colorectal cancer. Jama, 308(15), 1555-1565.

Reidy, E., Leonard, N. A., Treacy, O., \& Ryan, A. E. (2021). A 3D View of Colorectal Cancer Models in Predicting Therapeutic Responses and Resistance. Cancers, 13(2), 227.

Roberts, M. C., Mensah, G. A., \& Khoury, M. J. (2019). Leveraging implementation science to address health disparities in genomic medicine: examples from the field. Ethnicity \& disease, 29(Suppl 1), 187.

Schmeler, K. M., Lynch, H. T., Chen, L. M., Munsell, M. F., Soliman, P. T., Clark, M. B., \& Lu, K. H. (2006). Prophylactic surgery to reduce the risk of gynecologic cancers in the Lynch syndrome. New England Journal of Medicine, 354(3), 261-269.

Sehgal, R., Sheahan, K., O'Connell, P. R., Hanly, A. M., Martin, S. T., \& Winter, D. C. (2014). Lynch syndrome: an updated review. Genes, 5(3), 497-507.

Seppala, T., Pylvanainen, K., Renkonen, L., Bohm, J., Kuopio, T., Jarvinen, H. J., \& Mecklin, J. P. (2016). Diagnosis and treatment of lynch syndrome. Duodecim; laaketieteellinen aikakauskirja, 132(3), 233-240.

Sinicrope, F. A. (2018). Lynch syndrome-associated colorectal cancer. New England Journal of Medicine, 379(8), 764-773. 
Tiwari, A. K., Roy, H. K., \& Lynch, H. T. (2016). Lynch syndrome in the 21st century: clinical perspectives. QJM: An International Journal of Medicine, 109(3), 151-158.

Vasen, H. F., Blanco, I., Collan, K., Gopie, J. P., Alonso, A., Aretz, S., \& Moslein, G. (2013). Revised guidelines for the clinical management of Lynch syndrome (HNPCC): recommendations by a group of European experts. Gut, 62(6), 812-823.

Vasen, H. F., Watson, P., Mecklin, J. P., \& Lynch, H. T. (1999). New clinical criteria for hereditary nonpolyposis colorectal cancer (HNPCC, Lynch syndrome) proposed by the International Collaborative group on HNPCC. Gastroenterology, 116(6), 1453-1456.

Yurgelun, M. B., \& Hampel, H. (2018). Recent advances in lynch syndrome: diagnosis, treatment, and cancer prevention. American Society of Clinical Oncology Educational Book, 38, 101109. 